\title{
Predicted Total Body Clearance Rate
}

National Cancer Institute

\section{Source}

National Cancer Institute. Predicted Total Body Clearance Rate. NCI Thesaurus. Code C85797.

The predicted total body clearance for intravascular administration. 